\title{
Facing policy challenges with inter- and transdisciplinary soil research focused on the UN Sustainable Development Goals
}

\author{
Johan Bouma $^{1}$ and Luca Montanarella ${ }^{2}$ \\ ${ }^{1}$ Formerly Soils Department, Wageningen University, Wageningen, the Netherlands \\ ${ }^{2}$ Joint Research Centre, European Commission, Ispra, Italy \\ Correspondence to: Johan Bouma (johan.bouma@planet.nl)
}

Received: 14 January 2016 - Published in SOIL Discuss.: 5 February 2016

Revised: 22 March 2016 - Accepted: 9 April 2016 - Published: 20 April 2016

\begin{abstract}
Our current information society, populated by increasingly well-informed and critical stakeholders, presents a challenge to both the policy and science arenas. The introduction of the UN Sustainable Development Goals (SDGs) offers a unique and welcome opportunity to direct joint activities towards these goals. Soil science, even though it is not mentioned as such, plays an important role in realizing a number of SDGs focusing on food, water, climate, health, biodiversity, and sustainable land use. A plea is made for a systems approach to land use studies, to be initiated by soil scientists, in which these land-related SDGs are considered in an integrated manner. To connect with policy makers and stakeholders, two approaches are functional. The first of these is the policy cycle when planning and executing research, which includes signaling, design, decision making, implementation, and evaluation. Many current research projects spend little time on signaling, which may lead to disengagement of stakeholders. Also, implementation is often seen as the responsibility of others, while it is crucial to demonstrate - if successful - the relevance of soil science. The second approach is the DPSIR approach when following the policy cycle in land-related research, distinguishing external drivers, pressures, impact, and responses to land use change that affect the state of the land in the past, present, and future. Soil science cannot by itself realize SDGs, and interdisciplinary studies on ecosystem services (ESs) provide an appropriate channel to define contributions of soil science in terms of the seven soil functions. ESs, in turn, can contribute to addressing the six SDGs $(2,3,6,12,13$, and 15) with an environmental, land-related character. SDGs have a societal focus and future soil science research can only be successful if stakeholders are part of the research effort in transdisciplinary projects, based on the principle of time-consuming "joint learning". The internal organization of the soil science discipline is not yet well tuned to the needs of inter- and transdisciplinary approaches.
\end{abstract}

\section{Introduction}

This paper will discuss the relationships between policy and sustainability research focusing on soil science, realizing that societies have been subject to major changes in the recent past. Twenty years ago, the internet had hardly established itself (Hilbert and Lopez, 2011). Now, billions of people have computers and mobile phones and unlimited access to an overwhelming quantity of "open" data and information via the World Wide Web (Robinson, 2015). Scientists are not the only source of information anymore as they were in the not too distant past, at least in their own perception. Rather than deliver information by communicating results of their research, they are now increasingly faced with the challenge of judging information provided by the Web and channeling it to interested stakeholders. Also, stakeholders have become more knowledgeable and critical. A recent analysis showed that more than $50 \%$ of young Dutch farmers has a BSc or MSc degree (Van der Meulen et al., 2015). These societal changes had a major impact on not only the policy arena, 
where citizens become more active outside the traditional political party systems, but also on the relation between science and society. Rather than be just recipients of information, citizens are increasingly partners in "joint-learning" processes. This applies not only to countries considered developed but also increasingly to developing countries, where mobile phones are the primary source of an information revolution. It appears that the soil science community, like other disciplines, is struggling to catch up with these modern developments as many traditional procedures in this profession, established in the 19th century, appear to be quite strongly entrenched.

The effects of societal changes on policy and science will be discussed with the objective of exploring future possibilities for creative and productive interactions between the policy and scientific arenas, with particular attention paid to the role of soil science research when presenting effective contributions towards the achievement of sustainable development goals.

\section{The policy arena: science meeting society}

A policy is a statement of intent and a deliberate system of principles to guide decisions and achieve rational outcomes after implementation. The policy cycle consists of a number of phases (e.g., Althaus et al., 2007; Bouma et al., 2007): (i) the signaling phase, in which problems are identified, based on a characterization of current conditions; (ii) the $d e$ sign phase, in which options for possible corrective action are defined based on research using existing and newly acquired information; (iii) the decision phase, in which a selection is made by policy makers of options being presented - here, negotiation processes play an important role; (iv) the implementation phase in, which the selected option is being realized; and (v) the evaluation phase, in which the entire process is analyzed in terms of a learning procedure, applied to all participants. This may have to include monitoring procedures to document achievements. To be effective, all phases of the policy cycle require some form of interaction between stakeholders involved, governmental agencies, policy makers, and scientists. A good example is certainly the US Soil Conservation Act of 1935, responding to the severe soil degradation processes leading to the well-known "dust bowl" syndrome that caused serious economic and social problems in that historical period of the United States. However, soil-related policies have only rarely completed the full policy cycle as described above. In Europe the attempt to reach the implementation phase of the proposed EU Soil Framework Directive was ultimately stopped by the lack of political will of some EU member states to go beyond the negotiation and decision phase.

Policies can be proactive and reactive, but the latter usually applies. An example is the Nitrate Directive (ND) (European Commission, 1991), which was initiated because of very high nitrate concentrations in groundwater in many European countries, following excessive fertilization practices in agriculture. A water quality threshold of $50 \mathrm{mg}$ nitrates $\mathrm{L}^{-1}$ had already been established in the literature. It would have been most logical to require measurements of nitrate concentrations in groundwater at different locations in order to compare these values with the threshold and then conclude whether or not quality was adequate. However, measurements of nitrate concentrations in water were cumbersome at the time, as well as costly and time consuming, and data were scarcely available. As any policy measure needs to be organized in such a way that operational procedures can ensue, an alternative "proxy" was selected in terms of a maximum fertilization rate of organic manure corresponding to $170 \mathrm{~kg} \mathrm{Nha}^{-1}$ (e.g., Bouma, 2011). This corresponds to the manure production of approximately 1.7 animals ha $^{-1}$, which can be easily controlled by regulators because the numbers of animals and hectares are known for each farm. Groundwater quality in the late 1980s was considered to be quite poor in many areas and measures had therefore to be taken quickly: the signaling, design, decision, and implementation phases of the policy cycle followed very rapidly. The $170 \mathrm{~kg} \mathrm{Nha}^{-1}$ was not based on research, i.e., relating different application rates of fertilizers to nitrate enrichment of groundwater as a function of weather and soil conditions, but was essentially empirical in nature. Science played a role only as problem recognizer, documenting high nitrate contents of groundwater. After 25 years, this policy has been quite successful in the Netherlands (e.g., Bouma, 2016). Average nitrate contents in groundwater in sandy soils were $190 \mathrm{mg} \mathrm{L}^{-1}$ in 1991 , which was far above the critical threshold. After introduction of the ND in 1991, contents have gradually decreased, and in 2012 the average content corresponded to the threshold. However, contents in sandy soils were lower than the threshold in the northern part of the country and are still higher in the southern part. Nitrate contents in clay soils were still $80 \mathrm{mg} \mathrm{L}^{-1}$ in 1998 but decreased to $20 \mathrm{mg} \mathrm{L}^{-1}$ in 2012 , while contents in peat soils were always lower than the threshold. Loess soils in the southern tip of the country had higher contents than $50 \mathrm{mg} \mathrm{L}^{-1}$ in 2012 , but these soils only occupy a small area and their very deep water tables create quite different conditions (http://www.rivm.nl/Onderwerpen/ L/Landelijk_Meetnet_effecten_Mestbeleid). Other problem areas, such as the quality of surface waters and nature areas, are discussed elsewhere (Bouma, 2016). Possibly due to the apparent success of the ND, attention has not yet been raised for an in-depth evaluation phase of the policy cycle; this will be discussed later in more detail.

Restricting attention to the ND, should the role of science be different in the future, and, if so, why? 


\section{The changing roles of science and policy in the information society.}

The internet was only present in a rudimentary form in 1991 (Hilbert and Lopez, 2011). Now, the vast majority of people are connected to the internet by computer or mobile phone, and this is also true for many developing countries. The World Wide Web creates an enormous flow of information, and scientists are increasingly engaged in interpreting and screening information that reaches and often confuses users, stakeholders, and policy makers alike. At the same time, well-educated users ask ever more pertinent and critical questions. The roles of the various participants in the societal debate that seemed rather well defined even 30 years ago have fundamentally changed. Authority is gained by the quality of what is presented, not by the position of the presenters. Some see contributions of science as "just another opinion" and feel that science has to regain its "license to operate". How can this be dealt with? And how do these effects influence policy makers?

Confronted with citizens of the knowledge democracy (In't Veld, 2010) and battered by social media that react instantly to policy measures, and preferably to policy failures, policy makers and regulators become highly risk averse, avoiding controversy if at all possible. This invites neither introduction of innovative measures nor definition of clear goals for future action which may be controversial. Also, there is a tendency in many Western countries to decentralize decision making, providing more responsibilities to regional, provincial, or communal entities. Scientists therefore face not only more knowledgeable and critical stakeholders but also a more diverse group of policy makers. How can this be dealt with, and how can these new conditions be turned into an advantage by disruptive thinking, focusing on innovation? (e.g., Loorbach and Rotmans, 2010; Schot and Geels, 2008). A successful example of close linking of the scientific advice and the policy-making process is certainly the climate change policy arena. Here the main driver has been the well-recognized role of the Intergovernmental Panel on Climate Change (IPCC) in providing high-level, policy-relevant scientific advice through highly reliable assessments. This role of the IPCC gained its members a well-deserved Nobel Prize in 2007. The strength of the IPCC is that, while being an intergovernmental body nominated by governments, it also retains a very high scientific credibility within the scientific community. This allows the IPCC to deliver assessments that are fully endorsed by the related scientific community and fully accepted by the policy-making community as well. Such a crucial role of acting as a science-policy interface has also been identified as urgently needed for other multilateral environmental agreements (MEAs), like CBD and UNCCD. Indeed, the recently established Intergovernmental Platform for Biodiversity and Ecosystem Services (IPBES) has the ambition to serve like the IPCC as the science-policy interface for CBD and also for other related MEAs. The need for such a science-policy interface also for soils was well recognized in 2011 during the negotiations for the establishment of the Global Soil Partnership (GSP). Indeed, within the GSP, the Intergovernmental Technical Panel on Soils (ITPS) has been established and has now been in operation for three years (all abbreviations are explained in Appendix A). Its first assessment is the "Status of World's Soil Resources" report, released at the closing ceremony of the UN International Year of Soils 2015 (Montanarella and Alva, 2015).

\section{Signaling as a crucial element of the policy cycle focusing on the SDGs}

Despite all the societal changes that soil scientists are confronted with, the policy cycle still applies. Signaling requires definition of goals and an assessment as to whether current conditions allow goals to be reached when proper measures are taken or when this will not be possible defining drastic change. The recent 17 UN SDGs (Table 1) (http: //sustainabledevelopment.un.org/focussdgs.html) provide a valuable point of reference for the policy cycle and for signaling in particular. Soils are not an SDG goal by themselves, but they have a strong relation with food (SDG 2), health (SDG 3), water (SDG 6), climate (SDG 13), biodiversity (SDG 15), and sustainable development (several SDGs for soil science, particularly SDG 15, which mentions land degradation). None of these goals can be reached by just studying soils; instead, they require interdisciplinary approaches, including contributions by soil science that often have a significant effect on results. Examples for soilrelated studies for all these areas are presented by Keesstra et al. (2016). Health-related issues are becoming increasingly important. Tabor et al. (2011) presented a novel epidemiological study based on a landscape approach. Bonfante and Bouma (2015) used soil maps and simulation modeling to assess the spatial effects of irrigation practices on the growth of 11 maize hybrids, considering effects of climate change. Results allowed more efficient targeting of water allocation and choice of hybrids for different soil conditions. This was new and surprising for the hydraulic engineers and plant breeders involved, who had a rather traditional and static view of the soil science profession. The example shows the advantage of reaching out to other professions. More examples are available, and they should be communicated more clearly, demonstrating interdisciplinarity in practice.

SDGs are globally applicable and will have to be implemented during the next years by all national governments. Of crucial importance will be the way in which progress towards achieving each goal will be measured. The adoption of an agreed set of indicators therefore becomes of fundamental relevance for the implementation and evaluation phase of the SDGs. Introducing soil-related indicators for the SDGs that explicitly mention soil as a component would be desirable, but will be hampered by the well-known lack of basic 
Table 1. The 17 UN Sustainable Development Goals (http:// sustainabledevelopment.un.org/focussdgs.html).

\begin{tabular}{|c|c|}
\hline Goal 1 & End poverty in all its forms everywhere \\
\hline Goal 2 & $\begin{array}{l}\text { End hunger, achieve food security and improved } \\
\text { nutrition and promote sustainable agriculture }\end{array}$ \\
\hline Goal 3 & $\begin{array}{l}\text { Ensure healthy lives and promote well-being for } \\
\text { all at all ages }\end{array}$ \\
\hline Goal 4 & $\begin{array}{l}\text { Ensure inclusive and equitable quality education } \\
\text { and promote lifelong learning opportunities for } \\
\text { all }\end{array}$ \\
\hline Goal 5 & $\begin{array}{l}\text { Achieve gender equality and empower all } \\
\text { women and girls }\end{array}$ \\
\hline Goal 6 & $\begin{array}{l}\text { Ensure availability and sustainable management } \\
\text { of water and sanitation for all }\end{array}$ \\
\hline Goal 7 & $\begin{array}{l}\text { Ensure access to affordable, reliable, sustainable } \\
\text { and modern energy for all }\end{array}$ \\
\hline Goal 8 & $\begin{array}{l}\text { Promote sustained, inclusive and sustainable } \\
\text { economic growth, full and productive employ- } \\
\text { ment and decent work for all }\end{array}$ \\
\hline Goal 9 & $\begin{array}{l}\text { Build resilient infrastructure, promote inclusive } \\
\text { and sustainable industrialization and foster inno- } \\
\text { vation }\end{array}$ \\
\hline Goal 10 & Reduce inequality within and among countries \\
\hline Goal 11 & $\begin{array}{l}\text { Make cities and human settlements inclusive, } \\
\text { safe, resilient and sustainable }\end{array}$ \\
\hline Goal 12 & $\begin{array}{l}\text { Ensure sustainable consumption and production } \\
\text { patterns }\end{array}$ \\
\hline Goal 13 & $\begin{array}{l}\text { Take urgent action to combat climate change and } \\
\text { its impacts }\end{array}$ \\
\hline Goal 14 & $\begin{array}{l}\text { Conserve and sustainably use the oceans, seas } \\
\text { and marine resources for sustainable develop- } \\
\text { ment }\end{array}$ \\
\hline Goal 15 & $\begin{array}{l}\text { Protect, restore and promote sustainable use } \\
\text { of terrestrial ecosystems, sustainably manage } \\
\text { forests, combat desertification, and halt and re- } \\
\text { verse land degradation and halt biodiversity loss }\end{array}$ \\
\hline Goal 16 & $\begin{array}{l}\text { Promote peaceful and inclusive societies for sus- } \\
\text { tainable development, provide access to justice } \\
\text { for all and build effective, accountable and inclu- } \\
\text { sive institutions at all levels }\end{array}$ \\
\hline Goal 17 & $\begin{array}{l}\text { Strengthen the means of implementation and re- } \\
\text { vitalize the global partnership for sustainable de- } \\
\text { velopment }\end{array}$ \\
\hline
\end{tabular}

soil data and adequate soil monitoring systems in many nations of the world. A more realistic approach will be to use proxy indicators addressing the goals in a more holistic and integrated manner.
Table 2. Ecosystem services with an important soil component according to Dominati et al. (2014).

\begin{tabular}{ll}
\hline Provisioning services \\
\hline 1. & Provision of food, wood, and fiber \\
2. & $\begin{array}{l}\text { Provision of raw materials } \\
\text { 3. }\end{array}$ \\
& $\begin{array}{l}\text { Provision of support for human infrastructures and } \\
\text { Regulating services }\end{array}$ \\
\hline R. & Flood mitigation \\
5. & Filtering of nutrients and contaminants \\
6. & Carbon storage and greenhouse gas regulation \\
7. & Detoxification and the recycling of wastes \\
8. & Regulation of pests and disease populations \\
\hline Cultural services \\
\hline 9. & Recreation \\
10. & Aesthetics \\
11. & Heritage values \\
12. & Cultural identity \\
\hline
\end{tabular}

In general, the ecosystem service (ES) concept is suitable to express this interdisciplinary effort because disciplines by themselves cannot define ESs (Table 2) (De Groot et al., 2002; Dominati et al., 2014). The next step is to define the role of soils in contributing to the provision of ESs and then the seven soil functions of the European Commission (European Commission, 2006) can be considered (Table 3) (Keesstra et al., 2016). For example, SDG 2, to "end hunger, improve nutrition and promote sustainable agriculture", relates to the provisioning of ES 1, relating to food. But sustainable development also requires regulating ES 5, 6,7 , and 8 . Soil functions 2,3 , and 6 define the contributions that soil science can make to these more general ecosystem services, which, again, require not only an interdisciplinary but also transdisciplinary approach. Bouma et al. (2015) presented six transdisciplinary case studies, identifying relevant SDGs, ESs, and soil functions as an example of framing based on studies that were made and published in the past with a traditional scientific focus. The authors also concluded that, in three of the studies, existing knowledge was adequate to solve the problem being studied. In the remaining studies, new research was needed and defined based on observed gaps in existing knowledge. To avoid confusion, it is important to refer to general ecosystem services and to soil contributions towards those services to be articulated by the soil functions. Terms like soil services or soil ecosystem services should be avoided.

\section{The DPSIR system}

When studying SDGs, ESs, and the application of soil functions in the context of the policy cycle, the DPSIR system 


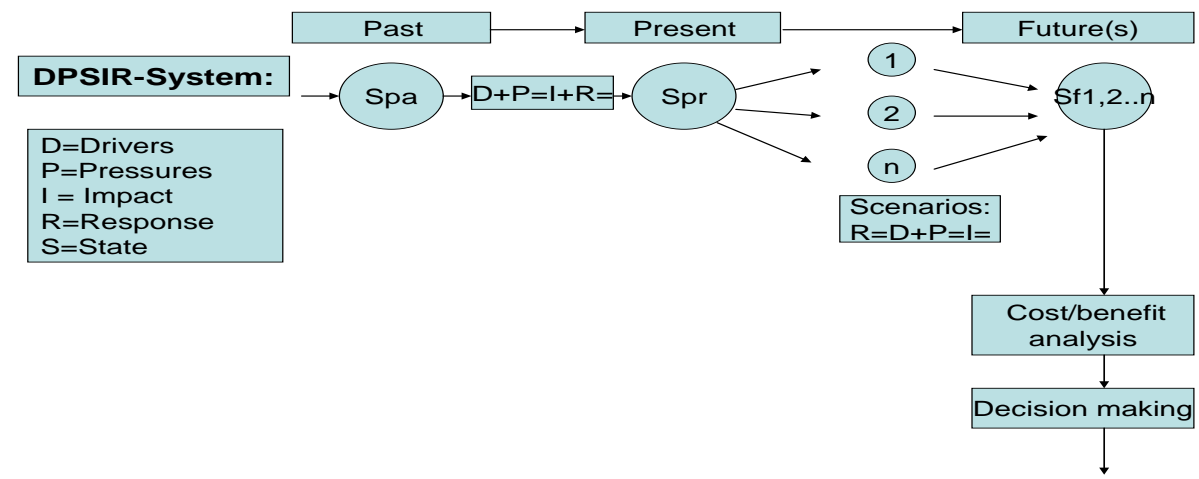

Figure 1. Future land use scenarios (Sf) (derived in consultation with stakeholders, policy makers, and colleague scientists), from which a choice has to be made in the policy arena. Which one represents sustainable development best? (S: status of the land defined in terms of the seven soil functions) (from Bouma, 2010).

Table 3. The seven soil functions as defined by the European Commission (2006).

\begin{tabular}{ll}
\hline 1 & Biomass production, including agriculture and forestry \\
\hline 2 & $\begin{array}{l}\text { Storing, filtering and transforming nutrients, substances } \\
\text { and water }\end{array}$ \\
\hline 3 & Biodiversity pool, such as habitats, species and genes \\
\hline 4 & $\begin{array}{l}\text { Physical and cultural environment for humans and hu- } \\
\text { man activities }\end{array}$ \\
\hline 5 & Source of raw material \\
\hline 6 & Acting as carbon pool \\
\hline 7 & Archive of geological and archaeological heritage \\
\hline
\end{tabular}

(Van Camp et al., 2004; Bouma et al., 2008) is helpful for analyzing processes involved (Fig. 1). Here, S represents the state of the land, D represents drivers of land use change, $\mathrm{P}$ represents the resulting pressures on the land, I is the impact, and $\mathrm{R}$ indicates a response in terms of development of strategies and operational procedures for the mitigation of perceived threats. The flowchart in Fig. 1 shows the past, present, and future state of the land. Drivers and pressures in the past have led to impacts and, most likely, certain responses. This all results in a present state which is not only determined by soil factors but can be defined by the ecosystem services it can provide by mobilizing relevant soil functions. This dynamic characterization of the state is preferred over a static one applying, for instance, a set of soil characteristics as has been the traditional approach in land evaluation (e.g., Bouma et al., 2012).

Of particular interest, of course, are future developments that are considered in terms of different scenarios, each one associated with characteristic drivers, pressures, and impacts. Different scenarios represent different visions on sustainability and have, of course, only an exploratory character. In the past scientists of different disciplines acted rather independently when assessing the various components of the DPSIR system and when defining scenarios, but today soil scientists would be well advised to interact with and engage colleagues in other sciences, stakeholders, and policy makers during the evaluation period to make sure that all options are considered and that their input is taken into account. This requires a truly transdisciplinary process (e.g., Klein et al., 2001). The combined scenarios, presenting a series of alternative options, are presented to the policy arena. Selection needs to be made by politicians and citizens, not by scientists. This is a crucial point because scientists should maintain their independence and should not be seen as partners in the policy arena or of certain business interests. Often, risk-averse politicians are more than willing to escape their responsibilities and hide behind scientists, which can be damaging to scientific reputation. The described scenario approach, defining a series of states with all its attributes, is therefore more appropriate than presenting only one, "ideal" option as defined, for example, by a group of scientists. When considering sustainable development, environmental, social, and economic considerations and approaches have to be mutually balanced to achieve some type of compromise that is acceptable to a wide range of stakeholders (be it grudgingly because their demands can only be partly met in the eventual compromise). Usually, economic considerations largely determine the outcome of this type of interdisciplinary analysis. The scheme in Fig. 1 suggests an approach where environmental and social aspects, expressed by DPSIR, are considered first and economic considerations come later in terms of a cost-benefit analysis for each of the Sf scenarios. The recently proposed soil security concept (McBratney and Field, 2015), distinguishing capability, condition, capital, connectivity, and codification, fits into the DPSIR scheme. The actual condition corresponds to $\mathrm{S}$ and also represents capital. Capability is represented by the scenarios in Fig. 1; connectivity with the required inter- and transdisciplinary approach and codifica- 
tion is the domain of legislators being fed relevant information.

This analysis indicates that the signaling phase of the policy cycle is very important because the option being chosen in the end is, ideally, the result of an extensive participatory process. If so, design can receive well-focused attention and decision making and implementation can follow rather quickly and harmoniously.

\section{Science versus policy in the real world}

As discussed, the introduction of the ND after 1991 did not follow the ideal policy cycle. Signaling, design, decision making, and implementation followed quickly because the groundwater quality issue was considered to be critical. In retrospect, the soil science community was successful in the preceding years in documenting the effect of different fertilizer practices on groundwater quality, but they paid no attention to what an enforceable policy to overcome the problem might look like. Policy makers had to act on their own. After 24 years, the policy has remained unchanged, while many questions are being raised. The universal application rate of $170 \mathrm{~kg} \mathrm{Nha}^{-1}$ does no justice to different processes in different soils and to effects of management. Examples are found where much higher application rates result in low nitrate contents in groundwater. In fact, the ND becomes a defacto means to restrict intensification of agriculture, which is a much broader policy goal (with major societal implications) than groundwater quality. Stakeholders are aware of this, and even though well-educated farmers support measures to enhance environmental quality, they resist "policy drift", when objectives secretly change in time. Also, they question what appear to be separate regulations for groundwater, surface water, air, and nature quality, while nutrient regimes are obviously related to all of them: nitrogen that moves into groundwater cannot be emitted to the air (e.g., Bouma, 2016). Recent studies carried out regarding Dutch dairy farms took a systems approach by applying a life cycle assessment for the entire farming operation, covering not only the emission of nutrients to both air and water but also net income and energy use (Dolman et al., 2014; De Vries et al., 2015). A group of eight farmers followed a nutrientcycling approach to reduce fertilizer use, and the results of their farming operations were compared with a control group. The program was highly interactive, involving intensive contact with farmers, demonstrating a good example of inter- and transdisciplinary research. There was time for signaling, design, and decisions by cooperating scientists and farmers, followed by implementation. The entire procedure took about 20 years. Farmers, following the nutrient cycling approach, had lower use of fertilizer and energy, lower emissions, and higher net incomes and organic matter contents of their soils due to management. But due to the high variability among farms, only energy use and organic matter contents

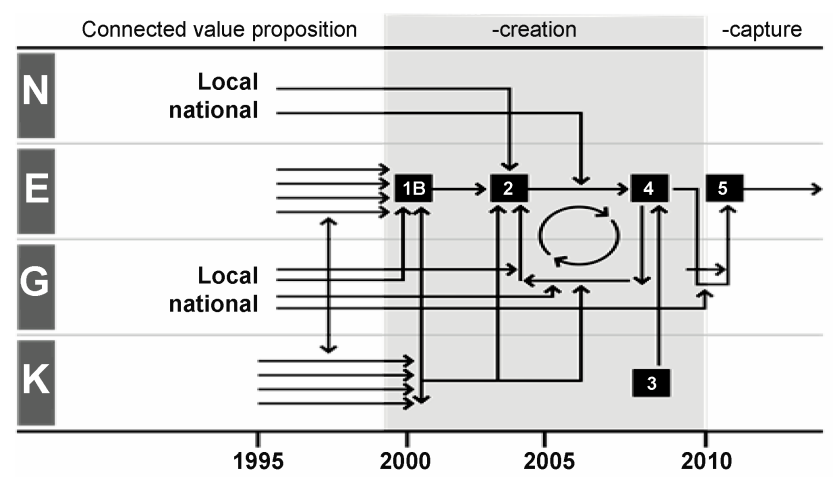

Figure 2. Schematic diagram showing complicated and longduration interaction patterns between different partners in a transdisciplinary study, developing a sustainable dairy system in the Netherlands. N: NGOs; E: entrepreneurs; G: government; K: the knowledge arena. In this study (Bouma et al., 2011), the policy cycle was simplified here by describing signaling as connected value proposition and design as -creation, which includes decision making, while implementation corresponds to -capture.

were significantly different when compared with a control group. Rather than focus on average values for a group of farmers, it would, in retrospect, have been preferable to focus on individual farms because every farm "has a different story to tell".

Droogers and Bouma (2014) studied accelerating future water shortages in Asia and Africa, requiring development of operational water governance models, as illustrated by three case studies: (1) upstream-downstream interactions in the Aral Sea basin, where the signaling function of science was most prominent; (2) impact and adaptation of climate change on water and food supply in the Middle East and North Africa, where not only signaling but also a broad design and a slow start in the implementation were important; and (3) Green Water Credits in Kenya, where the entire policy cycle was covered, including the start of implementation (Kauffman et al., 2014).

\section{From signaling to implementation}

Any impression that the sequence of signaling all the way to implementation represents a smooth, sequential process is, unfortunately, misleadingly simple. A major study on sustainable agriculture in the Netherlands showed that interactions between researchers, various stakeholders and policy makers were complex and repetitive, which can be shown in a diagram visualizing interaction processes. Figure 2 (from Bouma et al., 2011) illustrates this for case study 1 in Dutch dairy farms, the same study as the one mentioned above. Implementation could in the end only be achieved because the farmers involved, assisted by soil scientists, persisted against all odds. Kauffman et al. (2012) presented comparable diagrams for the Kenya study. 
The role of scientists in the implementation phase is different from the role in the signaling and design phase. In the latter, all opinions are welcome, as described above. But when plans and decisions have been made, implementation is a clear goal and distractions are rather unhelpful. Soil scientists can play an important role here by keeping the ultimate goal of the project in focus. It is also in their interest that specific results are obtained to document the beneficial effect of their input. Designs on paper of what appear to be most thoughtful and inventive projects have no impact and create no credit for all involved when they are not realized.

In Europe there are already existing soil-related policy instruments that are unfortunately lacking the necessary scientific backup and support from the soil science community. The most relevant example is the Common Agricultural Policy (CAP), probably one of the most important (at least in monetary terms) policies of the European Union (e.g., Montanarella, 2015). Obviously, there are major implications for soils when this policy is fully implemented. The mandatory requirement for "good agricultural and environmental conditions" (GAEC) that farmers need to implement in order to access the direct payment scheme of the CAP explicitly refers to soil parameters such as soil erosion, organic carbon, and compaction. Recent examples of dealing with GAEC illustrate its guiding potential (Panagos et al., 2015; Lugato et al., 2014). The correct implementation of such a crosscompliance scheme should have a substantial impact on soil conditions across the EU. Unfortunately, implementation has been rather weak, and monitoring of the results by an independent scientific community is essentially lacking. Soil scientists have missed an opportunity to play a key role in this process.

Current projects leave little time for scientists to be seriously engaged with both signaling and implementation, and this may have to be changed in future considering not only the demands but also the challenges and opportunities of the modern information society (e.g., Bouma, 2015).

\section{Soil science linking stakeholders and policy makers in the information society}

Changes in society, as discussed, have a strong impact on both the scientific and policy arena. Both struggle to communicate well with modern stakeholders and to define the role of science in the information age. When dealing with landrelated issues in the context of the SDGs, soil scientists are in an excellent position to become effective intermediaries in the stakeholder-policy-science nexus for at least two reasons. (i) Traditionally, soil scientists have worked intensively with stakeholders in the context of soil survey or soil fertility studies that involved extensive field work. This has decreased as soil surveys were completed and fertility schemes became well established. But traditions can be rejuvenated as a basis for truly transdisciplinary research that can genuinely en- gage stakeholders and provide broad support for policy measures. (ii) Moreover, even though soils are not mentioned in the SDGs, they form a cross-cutting theme in issues that do receive attention: water, climate, and biodiversity (e.g., Montanarella and Alva, 2015). This focus tends to unintentionally enforce the disciplinary nature of the water, climate, and biodiversity disciplines. Soil science, which is related to "land" more than any other discipline, can, in contrast, play a pioneering role in initiating system studies that integrate the various issues in a systems approach. Examples are the studies of Dolman et al. (2014) and De Vries et al. (2015). This type of study is attractive for stakeholders, like farmers, who have to operate complex production systems and for policy makers focusing on environmental quality, having to integrate separate requirements of water, air, and nature.

One final aspect needs to be considered. The ND legislation in 1991 had a "top-down, command-and-control" character which was realistic at the time because groundwater quality was poor in many locations and something had to be done quickly. However, after 25 years, the same top-down approach is still being followed at a time when not only environmental conditions have significantly improved but also the information society has drastically changed relations between policy and stakeholders, as discussed. Bouma (2016) therefore argued for a new "bottom-up" approach where tailor-made systems are designed for individual farms, including indicators that can be used for regulatory purposes. A "one-size-fits-all" approach does not satisfy anymore at a time when well-educated young farmers and other land users have access to many tools and sensors that allow on-site characterization of environmental conditions.

\section{Conclusions}

- Traditional procedures in both science and policy are increasingly at odds with the demands of the information society populated by well-informed, critical stakeholders. Soil scientists are in an excellent position to link the policy-stakeholder arenas when dealing with land-related environmental issues, accepting the SDGs as common goals. This will require not only interdisciplinary but also transdisciplinary research approaches covering the entire policy cycle from signaling to implementation.

- SDGs with an environmental focus can be approached by defining relevant ecosystem services that require an interdisciplinary research approach, including a disciplinary assessment of the role of soil functions when contributing to these ecosystem services.

- Current research programs tend to emphasize the design phase of the policy chain. More attention is needed for the signaling phase, where the DPSIR procedure can be effective, as well as in the design phase. Attention to 
implementation is needed to produce results supporting claims of relevance.

- "Top-down, command-and-control" environmental policy measures, as discussed here for the Nitrate Directive should be replaced by "bottom-up, interactive" approaches fed by "tailor-made" designs for individual enterprises using inter- and transdisciplinary research approaches. Only this approach is in line with the requirements of the information society in the 21 st century. 
Appendix A: List of abbreviations

\begin{tabular}{|c|c|}
\hline CAP & Common Agricultural Policy \\
\hline CBD & Convention on Biological Diversity \\
\hline DPSIR & $\begin{array}{l}\text { Drivers, pressures, state, impact, response re- } \\
\text { lated to land use change }\end{array}$ \\
\hline $\mathrm{EC}$ & European Commission \\
\hline ES & Ecosystem services \\
\hline EU & European Union \\
\hline GSP & Global Soil Partnership \\
\hline IPBES & $\begin{array}{l}\text { Intergovernmental Platform for Biodiversity } \\
\text { and Ecosystem Services }\end{array}$ \\
\hline IPCC & Intergovernmental Panel on Climate Change \\
\hline ITPS & Intergovernmental Technical Panel on Soils \\
\hline MEA & Multilateral environmental agreements \\
\hline SDG & Sustainable Development Goal \\
\hline UNFCCC & UN Framework Convention on Climate Change \\
\hline UNCCD & UN Convention to Combat Desertification \\
\hline
\end{tabular}


Edited by: C. Stevens

\section{References}

Althaus, C., Bridgman, P., and Davis, G.: The Australia Policy handbook, 4th Edition, Allen and Unwin, Sydney, Australia, 2007.

Bonfante, A. and Bouma, J.: The role of soil series in quantitative Land Evaluation when expressing effects of climate change and crop breeding on future land use, Geoderma, 259-260, 187-195, 2015.

Bouma, J.: Implications of the knowledge paradox for soil science, Adv. Agron., 106, 143-171, 2010.

Bouma, J.: Applying indicators, threshold values and proxies in environmental legislation: A case study for Dutch dairy farming, Environmental Science and Policy, 14, 231-238, 2011.

Bouma, J.: Engaging soil science in transdisciplinary research facing wicked problems in the information society, Soil Sci. Soc. Am. J., 79, 454-458, doi:10.2136/sssaj2014.11.0470, 2015.

Bouma, J.: The importance of validated ecological indicators for manure regulations in the Netherlands, Ecol. Indic., 66, 301-305, doi:10.016/j.ecolind.2016.01.050, 2016.

Bouma, J., Stoorvogel, J. J., Quiroz, R., Staal, S., Herrero, M., Immerzeel, W., Roetter, R. P., van den Bosch, H., Sterk, G., Rabbinge, R., and Chater, S.: Ecoregional Research for Development, Adv. Agron., 93, 257-311, 2007.

Bouma, J., de Vos, J. A., Sonneveld, M. P. W., Heuvelink, G. B. M., and Stoorvogel, J. J.: The role of scientists in multiscale land use analysis: lessons learned from Dutch communities of practice, Adv. Agron., 97, 177-239, 2008.

Bouma, J., van Altvorst, A. C., Eweg, R., Smeets, P. J. A. M., and van Latesteijn, H. C.: The role of knowledge when studying innovation and the associated wicked sustainability problems in agriculture, Adv. Agron., 113, 285-314, 2011.

Bouma, J., Stoorvogel, J. J., and Sonneveld, W. M. P.: Land Evaluation for Landscape Units, Handbook of Soil Science, Second Edition, edited by: Huang, P. M., Li, Y., and Summer, M.: Chapter 34, CRC Press, Boca Raton, London, New York, 34-1-34-22, 2012.

Bouma, J., Kwakernaak, C., Bonfante, A., Stoorvogel, J. J., and Dekker, L. W.: Soil science input in Transdisciplinary projects in the Netherlands and Italy, Geoderma Regional, 5, 96-105, doi:10.1016/j.geodrs.2015.04.002, 2015.

De Groot, P., Wilson, M. A., and Boumans, R. M. J.: A typology for the classification and valuation of ecosystem functions, goods and services, Ecol. Econ., 41, 393-408, 2002.

De Vries, W., Kros, J., Dolman, M. A., Vellinga, T. H. V., de Boer, H. C., Sonneveld, M. P. W., and Bouma, J.: Environmental impacts of innovative dairy farming systems aiming at improved internal nutrient cycling: a multi-scale assessment, Sci. Total Environ., 536, 432-442, 2015.

Dolman, M. A., Sonneveld, M. P. W., Mollenhorst, H., and de Boer, I. J. M.: Benchmarking the economic, environmental and societal performance of Dutch dairy farms aiming at internal recycling of nutrients, J. Clean. Prod., 73, 245-252, doi:10.1016/j.jclepro.2014.02.043, 2014.

Dominati, E., Mackay, A., Green, S., and Patterson, M.: A soilchange based methodology for the quantification and valuation of ecosystem services from agro-ecosystems: A case study of pastural agriculture in New Zealand, Ecol. Econ., 100, 119-129, 2014.

Droogers, P. and Bouma, J.: Simulation modeling for water governance in basins, Int. J. Water Res. Dev., 30, 475-494, 2014.

European Commission (EC): Directive 91/676/EEC Concerning the Protection of Water Against the Pollution Caused by Nitrates from Agricultural Sources, Brussels, 1991.

European Commission (EC): Communication from the Commission to the Council, the European Parliament, the European Economic and Social Committee and the Committee of the Regions. Thematic Strategy for Soil Protection, COM 231 Final, Brussels, 2006.

Hilbert, M. and Lopez, P.: The world's technological capacity to store, communicate and compute information, Science, 332, 60$65,2011$.

In't Veld, R. J. (Ed.): Knowledge Democracy. Consequences for science, politics and media, Springer Verlag, Berlin, Heidelberg, 2010.

Kauffman, J. H., Droogers, P., Hunink, J. E., Mwaniki, B., Muchena, F. N., Gicheru, P. T., Bindraban, P. S., Onduru, D., Cleveringa, R., and Bouma, J.: Green Water Credits - exploiting its potential to enhance ecosystem services by reducing soil erosion in the Upper Tana basin, Kenya, Intern. J. of Biodiversity Science, Ecosystem Services and Management, 10, 133143, 2014.

Keesstra, S. D., Bouma, J., Wallinga, J., Tittonell, P., Smith, P., Cerdà, A., Montanarella, L., Quinton, J. N., Pachepsky, Y., van der Putten, W. H., Bardgett, R. D., Moolenaar, S., Mol, G., Jansen, B., and Fresco, L. O.: The significance of soils and soil science towards realization of the United Nations Sustainable Development Goals, SOIL, 2, 111-128, doi:10.5194/soil-2-1112016, 2016.

Klein, J., Grossenbacher-Mansuy, W., Häberli, R., Bill, A., Scholz, R. W., and Welti, M. (Eds.): Transdisciplinarity: joint problem solving among science, technology and society. An effective way for manageing complexity, Birkhauer Publ.Cie Basel, 2001.

Loorbach, D. and Rotmans, J.: The practice of transition management: examples and lessons from four distinct cases, Futures, 42, 237-246, 2010.

Lugato, E., Panagos, P., Bampa, F., Jones, A., and Montanarella, L.: A new baseline of organic carbon stock in European Agricultural soils using a modeling approach, Glob. Change Biol., 20, 313 326, doi:10.1111/gcb.12292, 2014.

McBratney, A. and Field, D.: Securing our soil, Soil Science and Plant Nutrition, 61, 587-591, doi:10.1080/00380768.2015.1071060, 2015.

Montanarella, L.: Agricultural policy: Govern our soils, Nature, 528, 32-33, doi:10.1038/528032a, 2015.

Montanarella, L. and Alva, I. L.: Putting soils on the agenda: The three Rio Conventions and the post-2015 development agenda, Current Opinion in Environmental Sustainability, 15, 41-48, doi:10.1016/j.cosust.2015.07.008, 2015.

Panagos, P., Borelli, P., and Robinson, D. A.: Common Agricultural Policy: tackling soil loss accross Europe, Nature, 526, 195, doi:10.1111/gcb.12292, 2015.

Robinson, D. A.: Moving toward data on soil change, Science, 347, 6218, doi:10.1111/gcb.12292, 2015.

Schot, J. and Geels, F. W.: Strategic niche management and sustainable innovation journeys: theory, findings, research agenda 
and policy, Technology analysis and Strategic Management, 20, 537-554, 2008.

Tabor, J. A., O'Rourke, M. K., Lebowitz, M. D., and Harris, R. B.: Landscape epidemiological study design to investigate an environmentally based disease, J. Expo. Sci. Env. Epid., 21, 197-211, 2011.

Van Camp, L., Bujarrabal, B., Gentile, A. R., Jones, R. J. A., Montanarella, L., Olazabel, C., and Selvaradjou, S. K.: Reports of the Technical Working Groups established under the Thematic Strategy for Soil Protection, EUR 2131'9EN/6, Office for the official publications of the European Commuinities, Luxembourg, 2004.
Van der Meulen, H., Matser, I., Remery, C., Terluin, I. and Bouma, J.: Agrarische jongeren: ambitieus en veelzijdig, Landb.Econ.Inst. (LEI) in samenwerking met Hogeschool Windesheim, Wageningen, 2015. 